\title{
Metabolic analysis of the effect of rheum on a taurocholate- induced acute pancreatitis rat model
}

\author{
Zhonghua Chen ${ }^{1,2}$, Li Shen ${ }^{1}$, Changyong Yang ${ }^{1}$, Jinghui Jiang ${ }^{1}$, Xing Liu ${ }^{3, *}$
}

\begin{abstract}
${ }^{1}$ Department of Pharmacology, West China School of Pharmacy, Sichuan University, Chengdu, People's Republic of China, ${ }^{2}$ Key laboratory of Drug Targeting, Ministry of Education, West China School of Pharmacy, Sichuan University, Chengdu, People's Republic of China, ${ }^{3}$ Department of Orthopaedic Surgery, The Children's Hospital Chongqing Medical University,

Chongqing, People's Republic of China
\end{abstract}

\begin{abstract}
The effects of rheum on serum parameters in a taurocholate-induced acute pancreatitis (AP) rat model were investigated using pathological and biochemical tests, and a proton nuclear magnetic resonance $\left({ }^{1} \mathrm{H}\right.$ NMR)-based metabonomic strategy. Healthy rats and rats with AP were either treated with rheum (7.5\% at a dose of $1.5 \mathrm{~g} / \mathrm{kg}$ ) or left untreated. Serum samples were collected from the AP and rheum-treated groups at 6,12 , and $24 \mathrm{~h}$ after treatment. The effect of rheum on pathological changes in the pancreatic was investigated to validate the AP model. We obtained ${ }^{1} \mathrm{H}$ NMR spectra and analyzed the results using the partial least squares discriminant method. The results of the pathological and metabolic analyses revealed an amelioration of multiple metabolic abnormalities and an increase in the aerobic respiration ratio after treatment, compared with the AP groups. These results were attributed to improvements in energy supply and the elimination of metabolic products. The study also promoted NMR-based metabonomic analysis as a feasible method of assessing traditional Chinese drugs.
\end{abstract}

Uniterms: Rheum/effects. Acute pancreatitis/analysis. Metabolomics. ${ }^{1} \mathrm{H}$ NMR. Pathological changes. Rats.

\section{INTRODUCTION}

Pancreatitis is inflammation of the pancreas, including aseptic, bacterial, and chronic non-specific inflammation, and specific inflammation caused by tuberculosis or parasites. Acute pancreatitis (AP), chronic pancreatitis, and specific pancreatitis are the most common clinical types (Crocker, 2012), of which AP is associated with the highest morbidity and mortality (Barreto, Rodrigues, 2008). Evidence indicates that pancreatin-induced autodigestion of the pancreatic tissue can lead to acute chemical inflammation in AP (Markus, 2013). However, there is currently no effective clinical treatment for AP owing to its complex pathophysiology and pathogenesis (Braganza, 2001; Gaisano, Gorelick, 2009; Kostyrnoi, 2012).

Rheum is a perennial herbaceous plant of the

\footnotetext{
*Correspondence: X. Liu. Department of Orthopaedic Surgery, The Children's Hospital Chongqing Medical University, Chongqing, 400014, P. R. China. E-mail: 1915377569@qq.com
}

Polygonaceae family. According to the Pharmacopoeia of the People's Republic of China 2010 (Chinese Pharmacopoeia Commission, 2010), the dry roots or rhizomes of Rheum palmatum L., Rheum tangguticum Maxim. ex Balf, and Rheum officinale Baill are the standard medicinal portions of rheum. Rheum has been used widely in traditional Chinese medicine to treat numerous commonly encountered diseases such as acute abdominal disorders (Chinese Pharmacopoeia Commission, 2010). Zhang et al. (2004) reported that patients who received integrated traditional Chinese medicine-western medicine (TCM-WM) presented with lower mortality $(10.77 \%)$ than those who received monotherapy (40.52\%). Moreover, classic ancient books and records mention the use of rheum as therapy for AP (Jiangsu New Medical College, 1997; Xiao, 2002). With the development of integrated TCM-WM, rheum has become one of the main components of traditional Chinese medicine. The role of rheum in a variety of effective treatments has been explored in several studies (Ge, Chen, Wang, 2008; Gu, Wang, 2009; Gao, He, 2007). 
Metabolomics is a systemic approach to metabolism research by analysis of metabolite profiles in the body fluids of an organism, followed by comparison of the variations induced by external stimuli or genovariation (Nicholson, Lindon, Holmes, 1999). Nuclear magnetic resonance (NMR), which has been very useful for characterizing physiological metabolites in biofluids, is one of the techniques used in metabolomics (Chen et al., 2012). However, analysis by NMR is difficult owing to the complexity of NMR spectral profiling arising from thousands of signals from endogenous molecules. Usually, principal component analysis (PCA), cluster analysis, and neuron analysis are coupled with NMR data analysis; PCA is the most popular technique. Partial least squares projection to latent structure discriminant analysis (PLS-DA), which is a PCA technique, is a type of supervised analysis related to unsupervised analysis. It can involve dividing the samples into groups before analysis, and ignoring random differences in existing groups (Zhang et al., 2013). Since 1999, metabonomics has been widely used to assess the pharmacological safety and toxicological mechanism of drugs in animal models. (Shi et al., 2007; Wei et al., 2008).

In the present study, we used a metabolomic approach involving proton nuclear magnetic resonance $\left({ }^{1} \mathrm{H}\right.$ NMR) spectroscopy with PCA to analyze samples from AP rat serum. PLS-DA was used to explore the differences among groups and to characterize the metabonomic metabolites. Furthermore, the effect of rheum on pancreatic pathology was also investigated to validate the AP rat model. The objectives of this research were: to demonstrate a new method of assessing traditional Chinese drugs; to investigate the oral potency of rheum in rat metabolism; to characterize alterations in metabolites after administering rheum to AP rat models; and to illustrate the underlying mechanisms.

\section{MATERIAL AND METHODS}

\section{Reagents}

Sodium taurocholate was acquired from Sigma ( $\mathrm{St}$ Louis, USA). Methanol, sodium dihydrogen phosphate, disodium hydrogen phosphate, and kits for measuring glucose, fatty acids, valine, histidine, and creatinine levels were purchased from the Huayi Company (Shanghai, China). Chloralhydrate was acquired from Kelun Pharmaceutical Co. (Chengdu, China). The Hypersil ODS2 column $(150 \times 4.6 \mathrm{~mm})$ was from Thermo Hypersil Co. (the United Kingdom).

\section{Test compound preparation}

Dried rheum root was acquired from Derentang Pharmacy (Chengdu, China) in August, 2009. To investigate the main constituents of the rheum, the root was ground into a powder and passed through a sieve (60 mesh). The contents of the sample powder were then investigated using high-performance liquid chromatography (HPLC). The powder was stored in a desiccated environment at room temperature until required. Aloe-emodin (110795200806), Physcion (110758-200610), Emodin (110756200710), Chrysophanol (0796-200705), and Rhein (0757200802) standardization controls were from the National Institute for the Control of Pharmaceutical and Biological Products.

\section{Mass detection}

The rheum was made into a suspension solution before our experiment commenced. The rheum powder $(7.50 \mathrm{~g})$ was added to approximately $100 \mathrm{~mL}$ boiled vehicle $(0.5 \%$ saline plus sodium carboxymethyl cellulose), mixed, and $100.0 \mathrm{~mL}$ was measured out. Finally, we obtained a well-distributed brownish yellow $7.5 \%$ rheum suspension. Afterwards, the rheum was analyzed in accordance with the Pharmacopoeia of the People's Republic of China 2010 (Chinese Pharmacopoeia Commission, 2010). The HPLC system, comprising a Hypersil ODS2 column $(150 \times 4.6 \mathrm{~mm})$ (Thermo Hypersil Co., United Kingdom) and methanol:0.1\% phosphate solution (85:15), operated at a volumetric flow rate of $1.0 \mathrm{~mL} \cdot \mathrm{min}^{-1}$, a wavelength of $254 \mathrm{~nm}$, and a temperature of $25^{\circ} \mathrm{C}$, was used to validate the mass of the crude drug. The HPLC chromatograms are shown in Figure 1.

By matching the retention times and peak area, the contents of the five principal components in rheum, i.e., Aloe-emodin, Physcion, Emodin, Chrysophanol, and Rhein, were determined to be $2.57,3.65,1.91,6.93$, and $1.01 \mathrm{mg} \cdot \mathrm{g}^{-1}$, respectively. All these five major components constituted $1.61 \%$ of the crude mixture, which met the quality requirements (not less than 1.5\%). Rheum was administered to the rats in this study.

\section{Animals}

The study was approved by the Institutional Animal Use and Care Committee of Sichuan University, and the protocol was compliant with the Guide for the Care and Use of Laboratory Animals. Male Wistar rats (250-300 g; free from specified pathogens) were supplied by Chengdu Dashuo Biotechnology Company Ltd. The animals were 

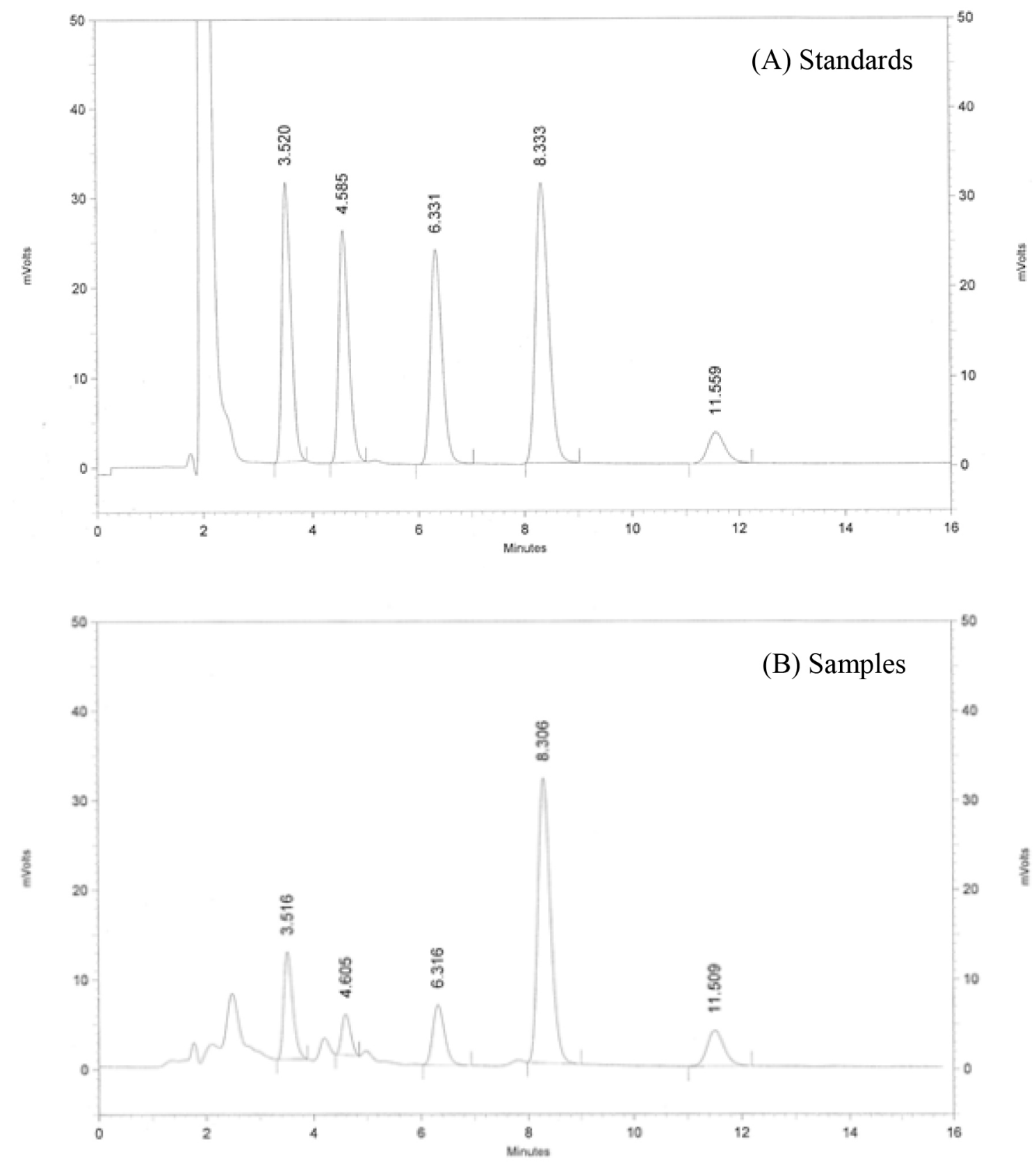

FIGURE 1 - High-performance liquid chromatography (HPLC) chromatograms of Standards (A) and Samples (B). 1. Aloeemodin $\left(t_{R}=3.516 \mathrm{~min}\right) ; 2$. Rhein $\left(t_{R}=4.605 \mathrm{~min}\right) ; 3$. Emodin $\left(t_{R}=6.316 \mathrm{~min}\right) ; 4$. Chrysophanol $\left(t_{R}=8.306 \mathrm{~min}\right) ; 5$. Physcion $\left(\mathrm{t}_{\mathrm{R}}=11.509 \mathrm{~min}\right)$

kept at the Animal Laboratory of Sichuan University under the following conditions: a $12 \mathrm{~h} \mathrm{light/dark} \mathrm{cycle;} \mathrm{free}$ access to standard laboratory feed and water; $20-24{ }^{\circ} \mathrm{C}$; and $50-60 \%$ humidity.

\section{Grouping and administration}

A total of 56 rats were randomly divided into eight groups: a 6-h AP group ( $(n=7)$, a 12-h AP group $(n=7)$, a 24-h AP group $(n=7)$, a 6-h medication group $(n=7)$, a 12-h medication group $(\mathrm{n}=7)$, a 24-h medication group $(n=7)$, a control group $(n=7)$, and a control-medication group $(\mathrm{n}=7)$.

The rats were all fasted for $12 \mathrm{~h}$ but had free access to water before the operation. Two hours before the operation, rats from the control-medication group, the 6-h medication group, the 12-h medication group, and the 24-h medication group were administered $7.5 \%$ rheum 
suspension (2 mL/100 g, intragastric administration (ig)), and the other groups were administered $0.5 \%$ sodium carboxymethyl cellulose in physiological saline solution ( $2 \mathrm{~mL} / 100 \mathrm{~g}$, ig).

\section{Operation}

The rats were anesthetized by intraperitoneal injection of $10 \%$ chloralhydrate $(0.3 \mathrm{~mL} / 100 \mathrm{~g})$. An incision (approximately $1 \mathrm{~cm}$ long) was made along the midline of the abdomen and the duodenum was clamped. A needle was inserted into the anterior wall of the duodenum close to the bile duct. When the needle had penetrated $1 \mathrm{~cm}$ into the choledoc, the biliopancreatic duct on the porta of the hepatic side was clamped using a small artery clamp, and physiological saline solution $(0.1 \mathrm{~mL} / 100 \mathrm{~g})$ (control and control-medication group) or $0.3 \%$ sodium taurocholate $(0.1 \mathrm{~mL} / 100 \mathrm{~g})$ (other AP and medication groups) was injected uniformly. After 5 min of injection, the artery clamp was removed and the abdomen was sutured.

\section{Sample collection}

The rats were sacrificed by femoral artery exsanguination under anesthesia at $6 \mathrm{~h}$ (6-h AP, 6-h medication, control, and control-medication groups), $12 \mathrm{~h}$ (12-h AP and 12-h medication groups), and $24 \mathrm{~h}$ (24-h AP and 24-h medication groups) after the operation. The blood samples were collected in centrifuge tubes and centrifuged $\left(4^{\circ} \mathrm{C}, 3000 \mathrm{rpm}, 10 \mathrm{~min}\right)$ to remove the precipitates. The serum samples were separated and stored at $-80^{\circ} \mathrm{C}$ for biochemical and metabonomic analysis. The pancreas was removed to provide specimens for pathological examination following blood collection.

\section{Pathological measurement and biochemical analysis}

The hiso-pancreas samples were fixed in $10 \%$ neutral formalin, embedded in paraffin, sectioned ( 5 $\mu \mathrm{m}$ ), and stained with hematoxylin and eosin (HE) for microscopic examination. The histopathological score of the hiso-pancreas was valued according to the Schmidt criteria (Norman et al., 1997; Banks et al., 2013) by the double-blind method. Serum samples were used for the determination of several major metabolites, including glucose $(50 \mu \mathrm{L})$, fatty acids $(50 \mu \mathrm{L})$, valine $(100 \mu \mathrm{L})$, histidine $(100 \mu \mathrm{L})$, and creatinine $(300 \mu \mathrm{L})$, using homologue kits.

\section{${ }^{1} \mathrm{H}$ NMR spectroscopic measurement and analysis}

After the biochemical tests, serum samples $(400 \mu \mathrm{L})$ were centrifuged $\left(4^{\circ} \mathrm{C}, 14000 \mathrm{rpm}, 10 \mathrm{~min}\right)$, and the supernatant was mixed with $50 \mu \mathrm{L} \mathrm{D}_{2} \mathrm{O}(99.8 \%, 0.5 \mathrm{~mL})$ and $50 \mu \mathrm{L}$ phosphate buffer solution $\left(0.2 \mathrm{~mol} / \mathrm{L} \mathrm{Na}_{2} \mathrm{HPO}_{4}\right.$ and $0.2 \mathrm{~mol} / \mathrm{L} \mathrm{NaH}_{2} \mathrm{PO}_{4}, \mathrm{pH} 7.4$ ) to minimize variations in the $\mathrm{pH}$ of the serum samples. The samples were transferred to 5-mm NMR tubes, and investigated using an ${ }^{1} \mathrm{H}$ NMR spectrometer at $600.13 \mathrm{MHz}$ (Bruker Av II 600 spectrometer). The water-suppressed Carr-PurcellMeiboom-Gill pulse (CPMG pulse) sequence method was used. The 64 free induction decay (FID) signals were represented by $64 \mathrm{~K}$ data points with a spectral width of $7002.8 \mathrm{~Hz}$, an acquisition time of $4.68 \mathrm{~s}$, and a total pulse recycle delay of $6.68 \mathrm{~s}$ at a temperature of $298 \mathrm{~K}$.

All NMR spectra were manually re-phased and baseline-corrected. The data were then reduced to 225 integrated regions of equal width $(0.04 \mathrm{ppm})$ corresponding to the $\delta 9.5-\delta 0.5$ region using the MestRe-C4.7 software package. The $\delta 5.0-\delta 4.6$ regions of the CPMG spectra were excluded to eliminate artifacts caused by the resonance of residual water. All the remaining spectral segments were scaled to the total integrated area of the spectrum to reduce variations in concentration.

The ${ }^{1} \mathrm{H}$ NMR spectra were all obtained by the same procedure, and all segments were imported into Microsoft Excel to obtain a $(7 \times 215)$-dimension matrix (the number of samples was 7; the number of segment regions outside $\delta 5.0-\delta 4.6$ was 215 ). The output files were fed into SIMCA-P11.0 software for PLS-DA to maximize the difference between groups. A plot of the scores was used to establish significance in the data, and the loading plots were used to identify different chemical shifts. Metabolites with different chemical shifts were assigned based on the human metabolome database (HMDB) (Wishart et al., 2007), and certain other related research articles (Yang et al., 1999; Bloomer, Stagliano, Gazzillo, 1993).

\section{RESULTS}

\section{Effect of rheum on pancreatic pathology in AP rats}

Pancreatic pathology was determined using the Schmidt scoring criteria. The Schmidt scores for pancreatic edema, acinar necrosis, hemorrhage, fat necrosis, inflammation, and perivascular infiltration were calculated. The rats in the control and control-medication groups were assigned a score of 0 on average. As illustrated 
in Figure 2, the rats in the AP groups scored higher than those in the medication groups for each pathological category at the same time-point, and the Schmidt score increased as time progressed after AP modeling in all groups. Similar pathological alterations were revealed by microscopic examination (Figure 3).

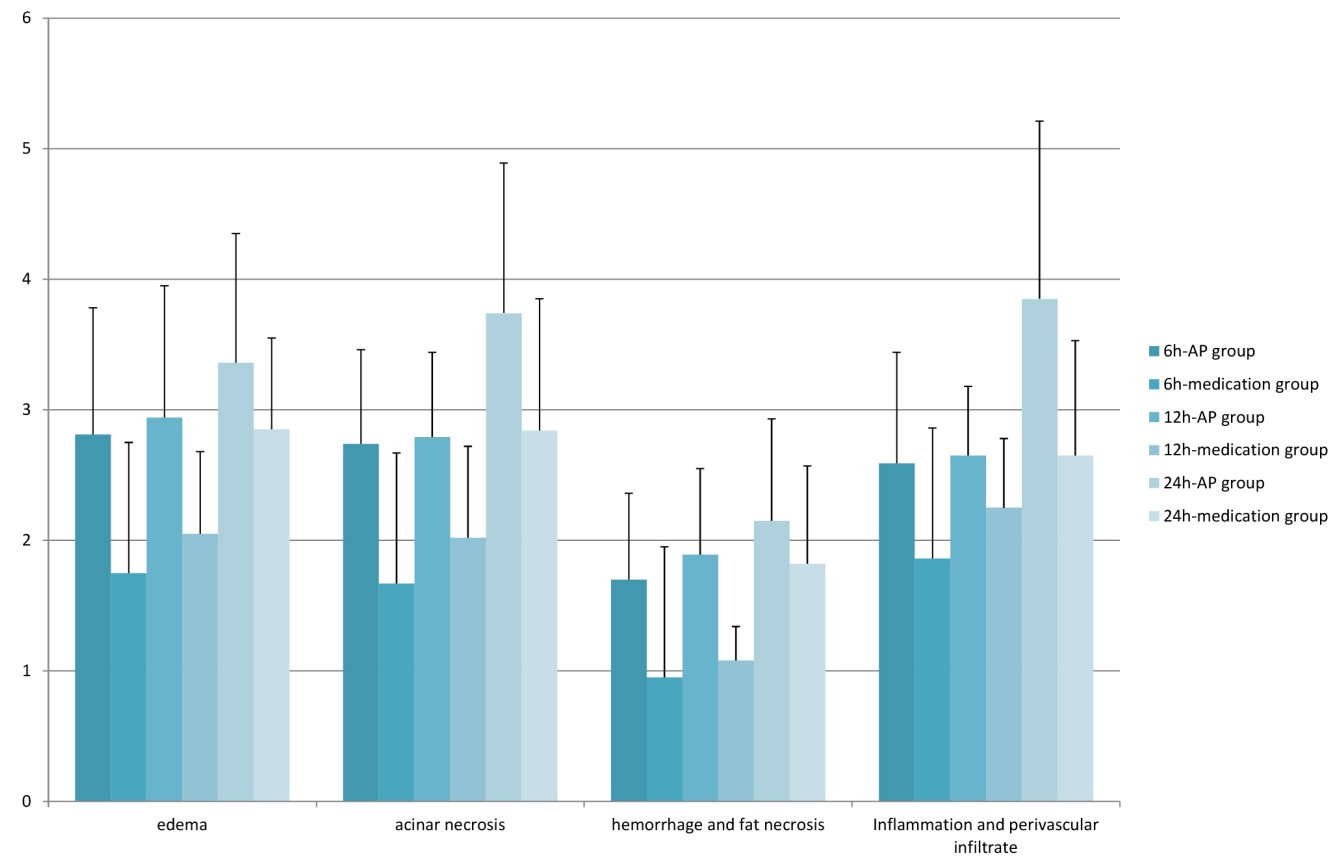

FIGURE 2 - Schmidt scores for the acute pancreatitis (AP) and medication groups. ${ }^{*} p<0.05$ for comparison between the corresponding groups (6-h AP group vs 6-h medication group; 12-h AP group vs 12-h medication group; 24-h AP group vs 24-h medication group).

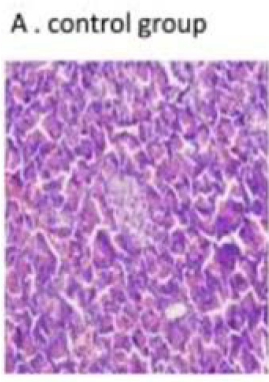

B. control medication group

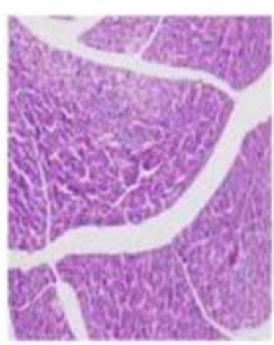

C. 6 h-AP group

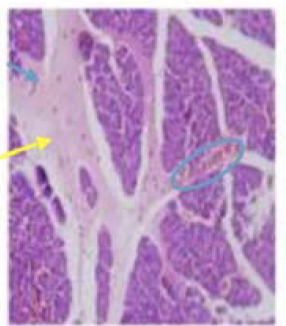

D.6h-medication group

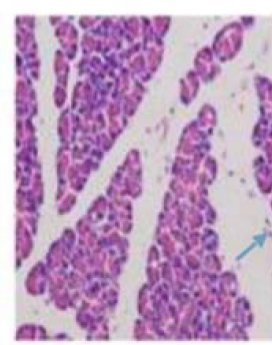

E. $12 \mathrm{~h}$-AP group

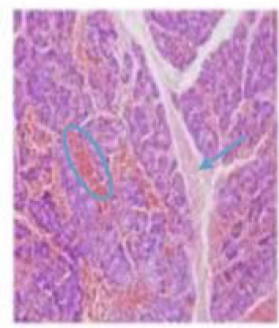

F. 12h-medication group

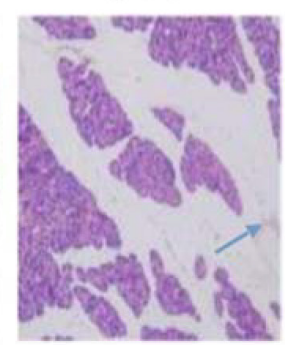

G. 24h-AP group

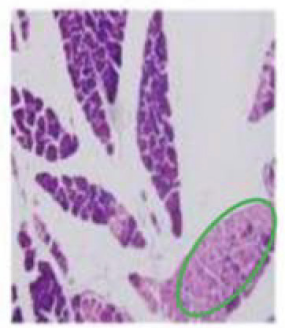

H.24h-medication group

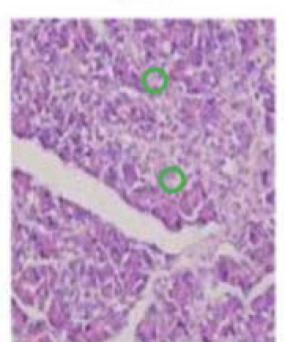

FIGURE 3 - Hematoxylin and eosin (HE) staining (200×). A, B: Normal pancreatic tissue with no pathological damage. C: Edema (indicated by the yellow arrow), inflammation infiltrate (indicated by the blue arrow), and mild hemorrhage (indicated by the blue oval) are evident. D: Inflammation infiltrate (indicated by the blue arrow) is less pronounced than in C. E: Infiltrate (indicated by the blue arrow) and severe hemorrhage (indicated by the blue oval) are clear. F: There is mild infiltrate (indicated by the blue oval). G: Severe acinar necrosis (indicated by the green oval). H: Less pronounced acinar necrosis compared with G (indicated by the green oval). 


\section{Biochemical analysis of serum samples}

The results of the biochemical analyses are reported in Table I. Compared with the control group, there were reduced glucose and increased fatty acid levels in the AP and AP medication groups ( $6 \mathrm{~h}, 12 \mathrm{~h}$, and $24 \mathrm{~h})$. For both valine and histidine, increases only occurred in the AP groups (6 h, $12 \mathrm{~h}$, and $24 \mathrm{~h})$. Serum creatinine levels in all the AP and AP medication groups $(6 \mathrm{~h}, 12 \mathrm{~h}$, and $24 \mathrm{~h}$ ) were much higher than in the control and controlmedication groups.

\section{PLS-DA analysis of serum samples}

We used PLS-DA to classify the differences among the groups and to characterize the metabolites that contributed to disparities. The $\delta 9.5-\delta 0.5 \mathrm{ppm}$ region was chosen for calculation of PLS-DA. According to the analysis of serum samples, the control group, the controlmedication group, the AP groups (6 h, $12 \mathrm{~h}$, and $24 \mathrm{~h}$ ), and the medication groups ( $6 \mathrm{~h}, 12 \mathrm{~h}$, and $24 \mathrm{~h}$ ) showed significant differences in chemical shifts, especially in the $\delta 3.00-\delta 4.00$ and $\delta 4.50-\delta 5.20$ regions. The analyses are described below.

\section{Control group and control-medication group}

Using the results for the serum samples from the control and control-medication groups, we calculated the principal component of the dedication rate of the first two values to be $94.77 \%$. Therefore, principal component values 1 and 2 were selected to draw the score plot (Figure 4). The control and control-medication groups were significantly separated along the t-axis on the plot (Ammann, Adler, Buchler, 2004), and there was an obvious distinction between the two groups. The possible main metabolites associated with the differences were then characterized using the loading plot (Figure 5). Compared with the control group, there were increases in cholestanone $(\delta 0.66, \delta 0.74), \beta$-hydroxybutyric acid $(\delta 1.34)$, succinic acid $(\delta 2.42)$, citric acid $(\delta 2.70), \alpha$-ketoglutaric acid $(\delta 2.98)$, malic acid $(\delta 4.30)$, testosterone $(\delta 5.74)$, emodin $(\delta 7.10)$, chrysophanol $(\delta 7.34)$, rhein $(\delta 7.42)$, 2,5 -dimethyl-7-methoxy chromone $(\delta 7.82, \delta 7.90)$, inosine

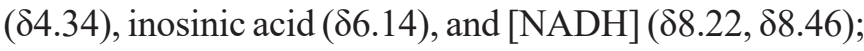
and decreases in lipids $(\delta 1.58, \delta 1.94, \delta 4.26)$, creatinine ( $\delta 3.02, \delta 3.94)$, bilirubin $(\delta 5.66)$, pteridine $(\delta 8.74)$, and $\left[\mathrm{NAD}^{+}\right](\delta 9.34)$.

\section{Control group and AP groups (6 h, 12 h, and $24 h)$}

Using the results for the serum samples from the control group and the three AP model groups (6 h, 12 $\mathrm{h}$, and $24 \mathrm{~h}$ ), we calculated the principal component of the dedication rate of the first two values to be $85.23 \%$. Therefore, principal component values 1 and 2 were selected to draw the score plot (Figure 6). The control and AP groups, especially the 6-h and 12-h AP groups, were separated along the t-axis on the plot (Ammann, Adler, Buchler, 2004). The possible main metabolites that contributed to differences were characterized based on the corresponding loading plot (Figure 7). Compared with the control group, there were increases in $\beta$-hydroxybutyric acid $(\delta 1.22, \delta 1.34)$, lactic acid $(\delta 1.42)$, acetoacetic acid $(\delta 2.26)$, valine $(\delta 2.30)$, deoxyadenosine $(\delta 2.82, \delta 6.42)$, creatinine $(\delta 3.02, \delta 3.06, \delta 3.94)$, trimethylamine-N-

TABLE I - Serum levels of major metabolites in the control, control-medication, and acute pancreatitis (AP) groups at 6 h, 12 h, and $24 \mathrm{~h}$; and in the medication groups at $6 \mathrm{~h}, 12 \mathrm{~h}$, and $24 \mathrm{~h}$

\begin{tabular}{lccccc}
\hline $\begin{array}{l}\text { Group } \\
(\mathbf{n}=\mathbf{7})\end{array}$ & $\begin{array}{c}\text { Glucose } \\
(\mathbf{m m o l} / \mathbf{L})\end{array}$ & $\begin{array}{c}\text { Fatty acid } \\
(\boldsymbol{\mu g} / \mathbf{L})\end{array}$ & $\begin{array}{c}\text { Valine } \\
(\mathbf{U} / \mathbf{m L})\end{array}$ & $\begin{array}{c}\text { Histidine } \\
(\mathbf{U} / \mathbf{m L})\end{array}$ & $\begin{array}{c}\text { Creatinine } \\
(\boldsymbol{\mu m o l} / \mathbf{L})\end{array}$ \\
\hline 6-h AP & $4.62 \pm 1.82^{\dagger}$ & $22.65 \pm 2.65$ & $15.24 \pm 5.24^{\dagger}$ & $52.54 \pm 2.54^{\dagger}$ & $167.88 \pm 67.88^{\dagger}$ \\
12-h AP & $3.57 \pm 1.29^{\dagger}$ & $23.54 \pm 3.54$ & $13.65 \pm 3.65^{\dagger}$ & $53.61 \pm 3.61^{\dagger}$ & $170.54 \pm 70.54^{\dagger}$ \\
24-h AP & $3.24 \pm 1.46^{\dagger}$ & $23.67 \pm 3.67$ & $14.55 \pm 4.55^{\dagger}$ & $51.93 \pm 1.93^{\dagger}$ & $199.52 \pm 99.52^{\dagger}$ \\
6-h medication & $4.77 \pm 1.76^{\dagger}$ & $38.99 \pm 8.99^{\dagger *}$ & $8.12 \pm 1.29^{*}$ & $32.55 \pm 2.55^{*}$ & $143.54 \pm 43.54^{\dagger}$ \\
12-h medication & $3.65 \pm 1.45^{\dagger}$ & $37.65 \pm 7.65^{\dagger *}$ & $8.04 \pm 0.45^{*}$ & $33.62 \pm 3.62^{*}$ & $156.21 \pm 56.21^{\dagger}$ \\
24-h medication & $3.44 \pm 1.73^{\dagger}$ & $38.04 \pm 8.04^{+*}$ & $7.91 \pm 9.14^{*}$ & $32.47 \pm 2.47^{*}$ & $178.52 \pm 78.52$ \\
Control-medication & $8.66 \pm 1.98$ & $20.77 \pm 0.20$ & $8.05 \pm 0.50$ & $33.02 \pm 3.02$ & $28.54 \pm 8.54^{\dagger}$ \\
Control & $8.48 \pm 2.52$ & $21.52 \pm 1.52$ & $7.94 \pm 0.94$ & $32.51 \pm 2.51$ & $49.54 \pm 9.54$ \\
\hline
\end{tabular}

$* p<0.05$ for comparison between the corresponding groups (6-h AP group vs 6-h medication group; 12-h AP group vs 12-h medication group; 24-h AP group vs 24-h medication group). ${ }^{\dagger} p<0.05$ vs control group. 


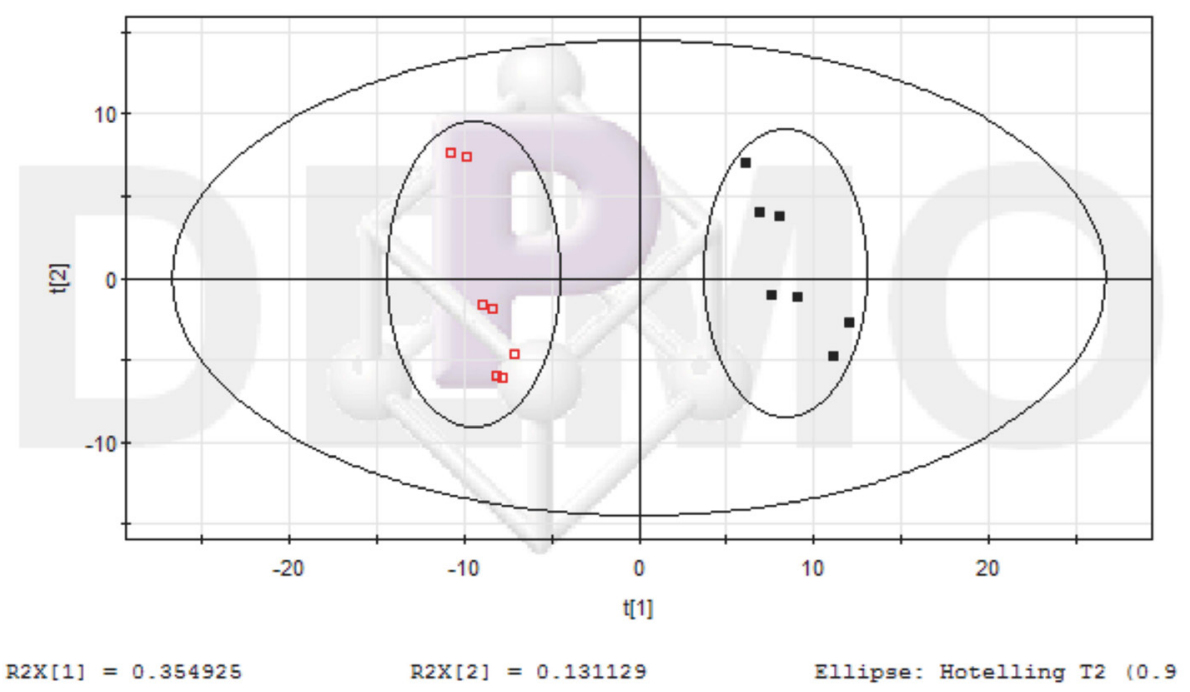

Key: $\square$ Class1: control group; $\square$ Class 2: control-medication group

FIGURE 4 - Score plot of the first two values of the proton nuclear magnetic resonance ( ${ }^{1} \mathrm{H}$ NMR) spectra of serum samples from the control and control-medication groups.

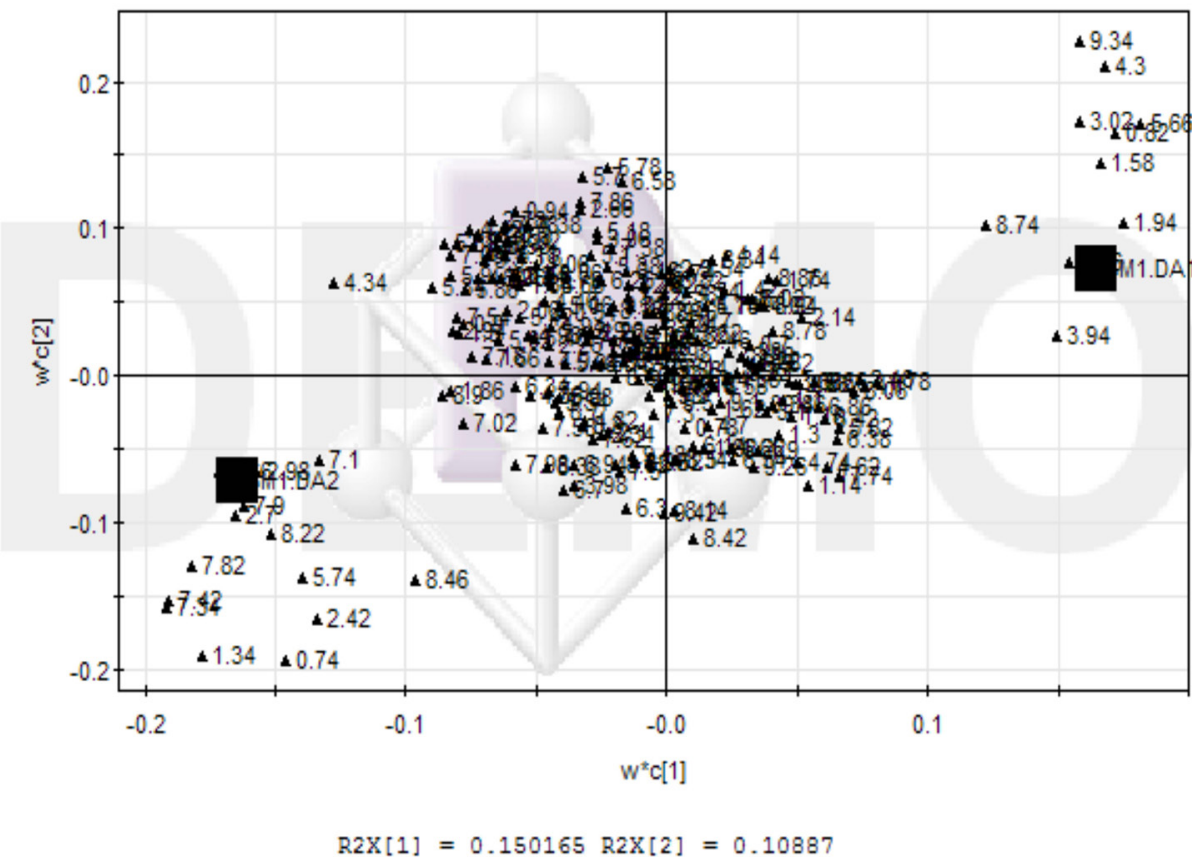

FIGURE 5 - Loading plot of the proton nuclear magnetic resonance ( ${ }^{1} \mathrm{H}$ NMR) spectra of serum samples from the control and control-medication groups.

oxide (TMAO) ( $\delta 3.26)$, urea nitrogen $(\delta 3.34, \delta 5.52$, $\delta 6.00)$, phosphoenolpyruvate $(\delta 5.18)$, adenine $(\delta 8.10)$, heteroauxin $(\delta 7.22)$, histidine $(\delta 7.30)$, phenylacetylglycine (PAG) $(\delta 7.34, \delta 7.42)$, hippuric acid $(\delta 7.54, \delta 7.58)$, pyrimidine $(\delta 7.62, \delta 8.82)$, and $\left[\mathrm{NAD}^{+}\right](\delta 9.34)$; and decreases in glucose $(\delta 2.94, \delta 3.70, \delta 3.86, \delta 4.34)$, 5-hydroxytryptamine (5-HT) ( $\delta 6.86)$, formic acid $(\delta 8.42)$, pteridine $(\delta 8.74)$, and $[\mathrm{NADH}](\delta 8.22)$.

\section{Control group and medication groups (6-h, 12-h, and 24-h)}

Using the results for the serum samples from the control group and the three medication groups (6-h, 12-h, and 24-h), we calculated the principal component dedication rate of the first two values to be $86.75 \%$. Therefore, the principal component values 1 and 2 were 


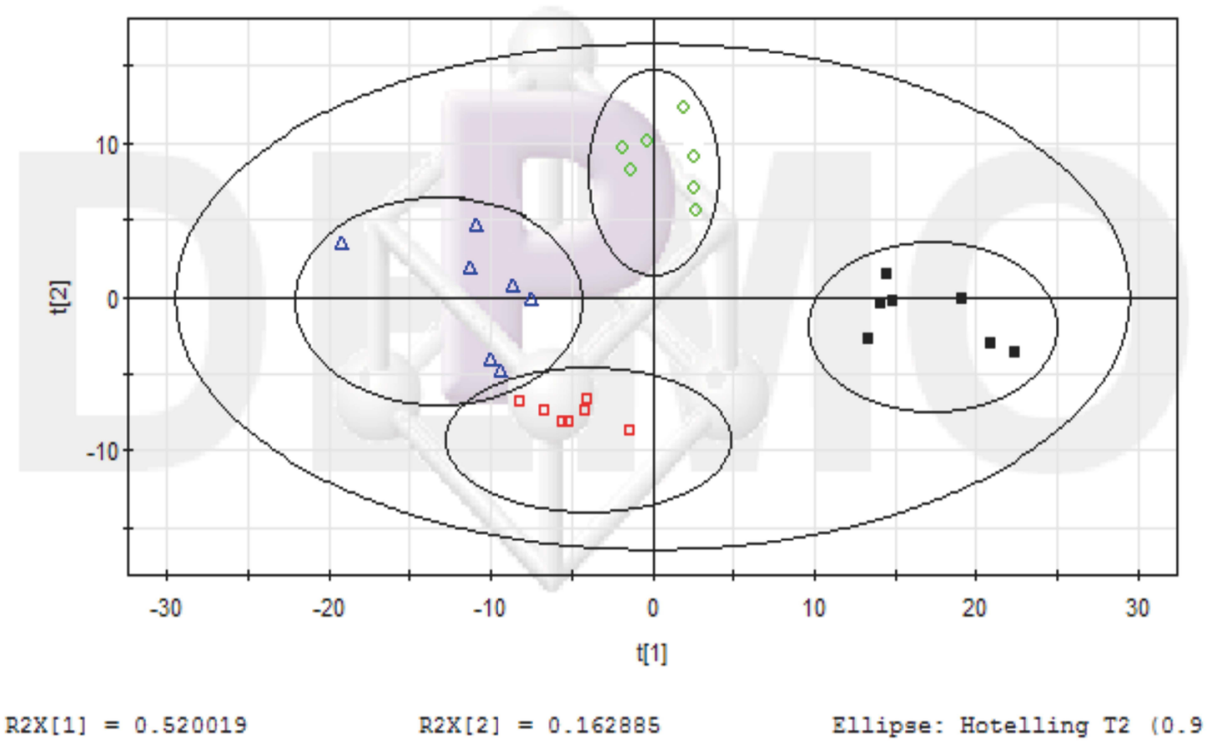

Key: $\square$ Class1: control group; $\quad$ Class 2: 6h-AP group; $\triangle$ Class3: $12 \mathrm{~h}-\mathrm{AP}$ group; oClass4: 24h-AP group

FIGURE 6 - Score plot of the first two values of the proton nuclear magnetic resonance ( ${ }^{1} \mathrm{H}$ NMR) spectra of serum samples from the control and acute pancreatitis (AP) groups (6-h, 12-h, and 24-h).

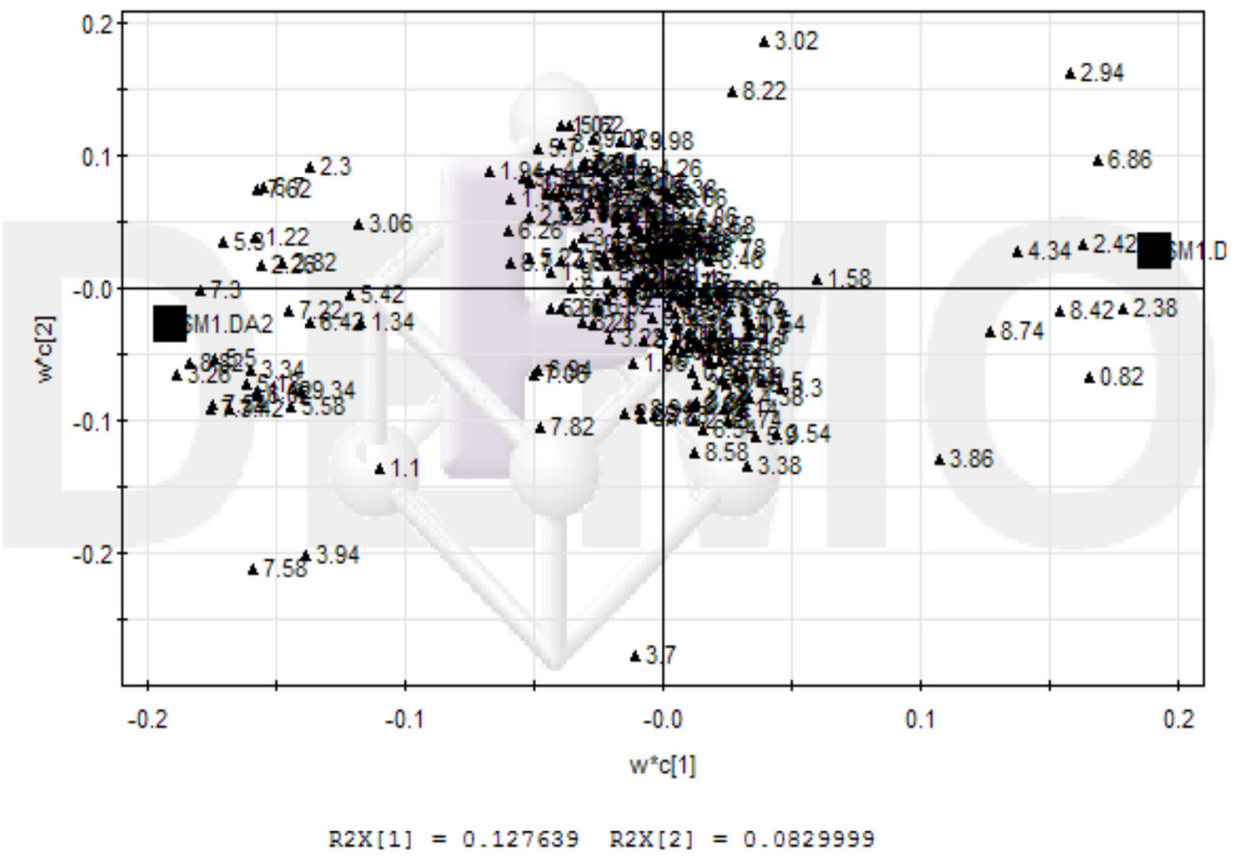

FIGURE 7 - Loading plot of the proton nuclear magnetic resonance ( ${ }^{1} \mathrm{H}$ NMR) spectra of serum samples from the control and acute pancreatitis (AP) groups (6-h, 12-h, and 24-h).

selected to draw the score plot (Figure 8). The control and medication groups (6-h and 12-h) were separated along the t-axis (Ammann, Adler, Buchler, 2004); differences were also observed among the 6-h, 12-h, and 24-h medication groups. The possible main metabolites contributing to differences were then characterized based on the corresponding loading plot (Figure 9). Compared with the control group, there were increases in fatty acids $(\delta 1.54, \delta 1.58)$, stearic acid $(\delta 1.74)$, lipids $(\delta 2.70, \delta 4.26)$, unsaturated fatty acid $(\delta 2.82)$, creatinine $(\delta 3.06, \delta 3.94)$, TMAO ( $\delta 3.26)$, hippurate $(\delta 3.98)$, lactic acid ( 84.10$)$, testosterone $(\delta 5.74)$, emodin $(\delta 6.66, \delta 7.10), 2,5$-dimethyl- 
7-methoxy chromone $(\delta 7.90)$, adenine $(\delta 8.10)$, PAG $(\delta 4.38, \delta 6.10, \delta 6.22)$, inosine $(\delta 4.34, \delta 8.18)$, inosinic acid $(\delta 6.14)$, and $[\mathrm{NADH}](\delta 4.38, \delta 6.10, \delta 6.22)$; and decreases in glucose $(\delta 4.34)$, bilirubin $(\delta 5.66)$, pteridine $(\delta 8.74)$, and $\left[\mathrm{NAD}^{+}\right](\delta 8.14, \delta 9.14, \delta 9.34)$.

\section{Summary}

The detailed variations in the endogenous metabolites detected in the serum samples indicated on the loadings plots are shown in Tables II and III.

\section{DISCUSSION}

In recent decades, various animal models have been established for AP research; the four most common models are induced by cerulein (Dembinski et al., 2008), L-arginine (Ji et al., 2003), DL-ethionine (Sewing, Albinus, 1969),

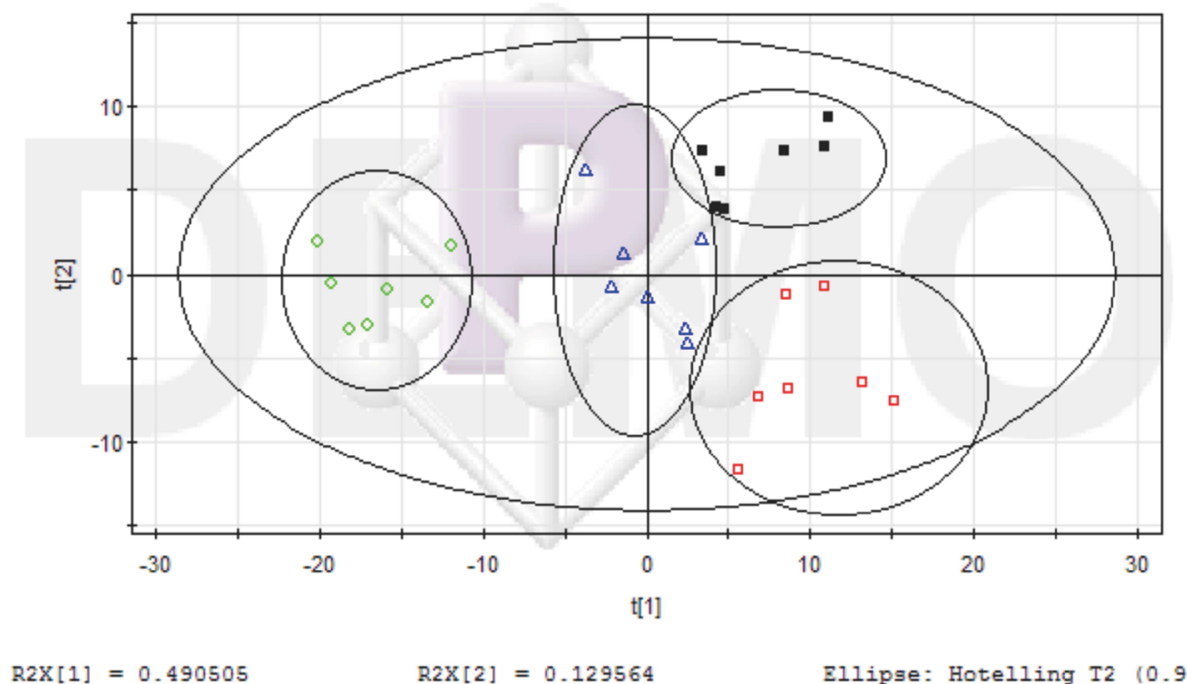

Key: $\square$ Class1: control group; $\square$ Class 2: $6 \mathrm{~h}$-medication group; $\triangle$ Class3: $12 \mathrm{~h}$ medication group; oClass4: 24h-medication group

FIGURE 8 - Score plot of the first two values of the proton nuclear magnetic resonance ( ${ }^{1} \mathrm{H}$ NMR) spectra of serum samples from the control and medication groups (6-h, 12-h, and 24-h).

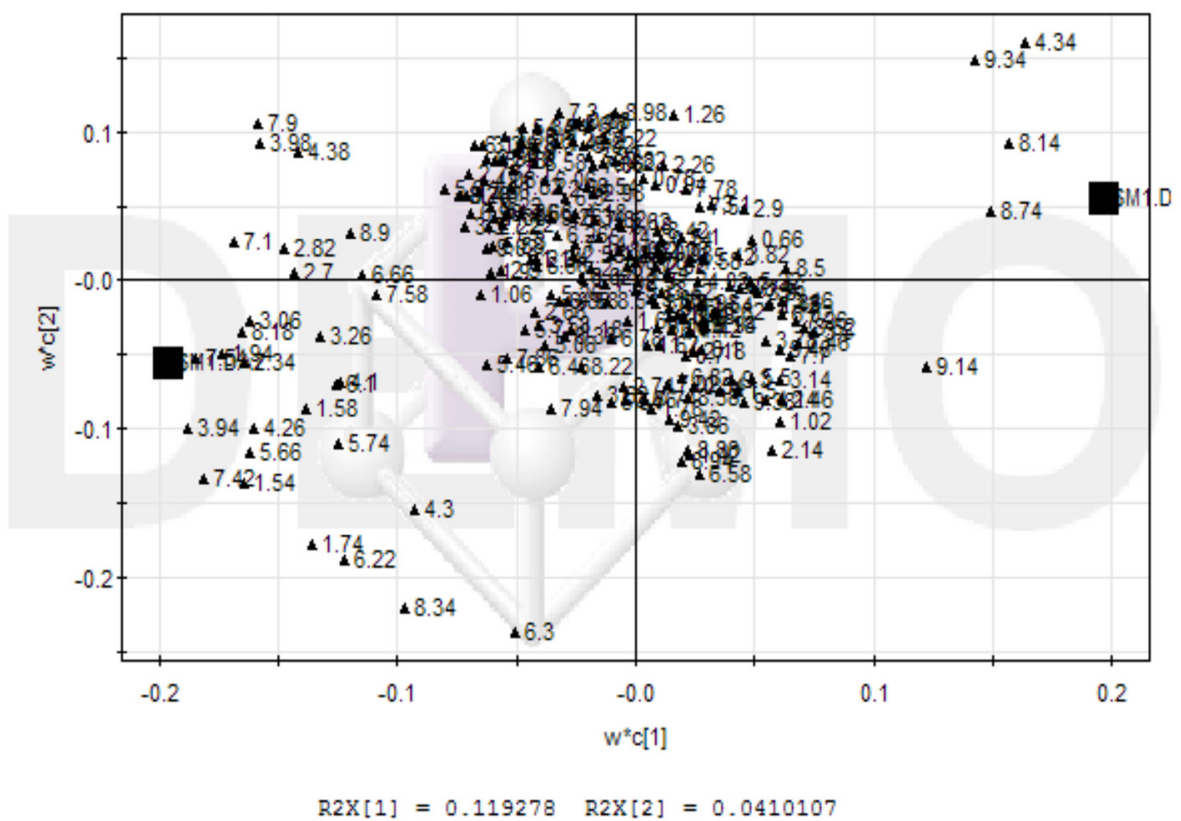

FIGURE 9 - Loading plot of the proton nuclear magnetic resonance ( ${ }^{1} \mathrm{H}$ NMR) spectra of serum samples from the control and medication groups (6-h, 12-h, and 24-h). 
TABLE II - Summary of the variations in metabolites detected in the serum samples from the control-medication group, the acute pancreatitis (AP) groups (6-h, 12-h, and 24-h), and the medication groups (6-h, 12-h, and $24 \mathrm{~h}$ ) compared with the control group

\begin{tabular}{|c|c|c|c|c|}
\hline Metabolites & $\begin{array}{c}\text { Chemical shifts } \\
(\delta)\end{array}$ & $\begin{array}{c}\text { Control- } \\
\text { medication } \\
\text { group }\end{array}$ & AP groups & $\begin{array}{c}\text { Medication } \\
\text { groups }\end{array}$ \\
\hline Emodin & $6.66,7.10$ & $\uparrow$ & - & $\uparrow$ \\
\hline Chrysophanol & 7.34 & $\uparrow$ & - & - \\
\hline Rhein & 7.42 & $\uparrow$ & - & - \\
\hline 2,5-dimethyl-7-methoxy chromone & $7.82,7.90$ & $\uparrow$ & - & $\uparrow$ \\
\hline Glucose & $\delta 2.94, \delta 3.70, \delta 3.86, \delta 4.34$ & - & $\downarrow$ & $\downarrow$ \\
\hline$\alpha$-Ketoglutaric acid & $\delta 2.98$ & $\uparrow$ & - & - \\
\hline Succinic acid & $\delta 2.38, \delta 2.42$ & $\uparrow$ & $\downarrow$ & - \\
\hline Malic acid & $\delta 4.30$ & $\uparrow$ & - & - \\
\hline Citric acid & $\delta 2.70$ & $\uparrow$ & - & - \\
\hline NADH & $\delta 4.38, \delta 6.10, \delta 6.22, \delta 8.22, \delta 8.46$ & $\uparrow$ & $\downarrow$ & $\uparrow$ \\
\hline$\left[\mathrm{NAD}^{+}\right]$ & $\delta 8.14, \delta 9.14, \delta 9.34$ & $\downarrow$ & $\uparrow$ & $\downarrow$ \\
\hline Fatty acids & $\delta 1.54$ & - & - & $\uparrow$ \\
\hline Stearic acid & $\delta 1.74$ & - & - & $\uparrow$ \\
\hline Lipids & $\delta 1.58, \delta 1.94, \delta 2.70, \delta 2.82, \delta 4.26$ & $\downarrow$ & - & $\uparrow$ \\
\hline$\beta$-hydroxybutyric acid & $\delta 1.22, \delta 1.34$ & $\uparrow$ & $\uparrow$ & - \\
\hline Acetoacetic acid & $\delta 2.26$ & - & $\uparrow$ & - \\
\hline Phosphoenolpyruvate & $\delta 5.18$ & - & $\uparrow$ & - \\
\hline Lactic acid & $\delta 1.42, \delta 4.10$ & - & $\uparrow$ & $\uparrow$ \\
\hline Indoleacetic acid & $\delta 7.22$ & - & $\uparrow$ & - \\
\hline Valine & $\delta 2.30$ & - & $\uparrow$ & - \\
\hline Histidine & $\delta 7.30$ & - & $\uparrow$ & - \\
\hline Creatinine & $\delta 3.02, \delta 3.06, \delta 3.94$ & $\downarrow$ & $\uparrow$ & $\uparrow$ \\
\hline Urea nitrogen & $\delta 3.34, \delta 5.50, \delta 6.02$ & - & $\uparrow$ & - \\
\hline Bilirubin & $\delta 5.66$ & $\downarrow$ & - & $\downarrow$ \\
\hline Adenine & $\delta 8.10$ & - & $\uparrow$ & - \\
\hline Pyrimidine & $\delta 7.62, \delta 8.82$ & - & $\uparrow$ & - \\
\hline Formic acid & $\delta 8.42$ & - & $\downarrow$ & - \\
\hline Inosine & $\delta 4.34, \delta 8.18$ & $\uparrow$ & - & $\uparrow$ \\
\hline Inosinic acid & $\delta 6.14$ & $\uparrow$ & - & $\uparrow$ \\
\hline Cholestanone & $\delta 0.66, \delta 0.74$ & $\uparrow$ & - & - \\
\hline Testosterone & $\delta 5.74$ & $\uparrow$ & - & $\uparrow$ \\
\hline TMAO & $\delta 3.26$ & - & $\uparrow$ & $\uparrow$ \\
\hline Pteridine & $\delta 8.74$ & $\downarrow$ & $\downarrow$ & $\downarrow$ \\
\hline Hippurate & $\delta 3.98$ & - & - & $\uparrow$ \\
\hline Hippuric acid & $\delta 7.54, \delta 7.58$ & - & $\uparrow$ & - \\
\hline PAG & $\delta 7.34, \delta 7.42$ & - & $\uparrow$ & $\uparrow$ \\
\hline 5-HT & $\delta 6.86$ & - & $\downarrow$ & - \\
\hline
\end{tabular}


TABLE III - Summary of the variations in metabolites detected in the serum samples from the medication groups compared with the acute pancreatitis (AP) groups

\begin{tabular}{|c|c|c|}
\hline Metabolites & Chemical shifts & AP-medication groups \\
\hline Emodin & $\delta 6.66, \delta 7.10$ & $\uparrow$ \\
\hline Chrysophanol & $\delta 7.34$ & - \\
\hline Rhein & $\delta 7.42$ & - \\
\hline 2,5-dimethyl-7-methoxy chromone & $\delta 7.82, \delta 7.90$ & $\uparrow$ \\
\hline Glucose & $\delta 2.94, \delta 3.70, \delta 3.86, \delta 4.34$ & - \\
\hline$\alpha$-Ketoglutaric acid & $\delta 2.98$ & - \\
\hline Succinic acid & $\delta 2.38, \delta 2.42$ & $\uparrow$ \\
\hline Malic acid & $\delta 4.30$ & - \\
\hline Citric acid & $\delta 2.70$ & - \\
\hline NADH & $\delta 4.38, \delta 6.10, \delta 6.22, \delta 8.22, \delta 8.46$ & $\uparrow$ \\
\hline$\left[\mathrm{NAD}^{+}\right]$ & $\delta 8.14, \delta 9.14, \quad \delta 9.34$ & $\downarrow$ \\
\hline Fatty acids & $\delta 1.54$ & $\uparrow$ \\
\hline Stearic acid & $\delta 1.74$ & $\uparrow$ \\
\hline Lipids & $\delta 1.58, \delta 1.94, \delta 2.70, \delta 2.82, \delta 4.26$ & $\uparrow$ \\
\hline$\beta$-hydroxybutyric acid & $\delta 1.22, \delta 1.34$ & $\downarrow$ \\
\hline Acetoacetic acid & $\delta 2.26$ & $\downarrow$ \\
\hline Phosphoenolpyruvate & $\delta 5.18$ & $\downarrow$ \\
\hline Lactic acid & $\delta 1.42, \delta 4.10$ & - \\
\hline Indoleacetic acid & $\delta 7.22$ & $\downarrow$ \\
\hline Valine & $\delta 2.30$ & $\downarrow$ \\
\hline Histidine & $\delta 7.30$ & $\downarrow$ \\
\hline Creatinine & $\delta 3.02, \delta 3.06, \delta 3.94$ & - \\
\hline Urea nitrogen & $\delta 3.34, \delta 5.50, \delta 6.02$ & $\downarrow$ \\
\hline Bilirubin & $\delta 5.66$ & $\downarrow$ \\
\hline Adenine & $\delta 8.10$ & $\downarrow$ \\
\hline Pyrimidine & $\delta 7.62, \delta 8.82$ & $\downarrow$ \\
\hline Formic acid & $\delta 8.42$ & $\uparrow$ \\
\hline Inosine & $\delta 4.34, \delta 8.18$ & $\uparrow$ \\
\hline Inosinic acid & $\delta 6.14$ & $\uparrow$ \\
\hline Cholestanone & $\delta 0.66, \delta 0.74$ & - \\
\hline Testosterone & $\delta 5.74$ & $\uparrow$ \\
\hline TMAO & $\delta 3.26$ & - \\
\hline Pteridine & $\delta 8.74$ & - \\
\hline Hippurate & $\delta 3.98$ & $\uparrow$ \\
\hline Hippuric acid & $\delta 7.54, \delta 7.58$ & $\downarrow$ \\
\hline PAG & $\delta 7.34, \delta 7.42$ & - \\
\hline $5-\mathrm{HT}$ & $\delta 6.86$ & $\uparrow$ \\
\hline
\end{tabular}

Note: $\uparrow$, increases; $\downarrow$, decreases; - , no change 
and sodium taurocholate (Lombardi, Estes, Longnecker, 1975). Of those, the sodium taurocholate-induced AP rat model exhibits high repeatability and an achievement ratio of $100 \%$. Moreover, topical administration of sodium taurocholate causes limited impairment of the other organs. Furthermore, the pathological changes after modeling are similar to those in pancreatitis caused by autodigestion of the pancreas tissue. In this study, we replicated the stability of a sodium taurocholate-induced AP rat model.

PLS-DA, which is a PCA technique, is a type of supervised analysis related to unsupervised analysis; it can involve dividing the samples into groups before analysis, and ignoring random differences between existing groups. Allowing for the grouping of animal serum samples in our test, the PLS-DA method was used to determine the differences between the metabonomic values found with rheum and the physiological metabonomic parameters among the other groups, and to characterize the metabolites on score and loading plots.

\section{Effect on pancreatic pathological changes}

According to the pancreatic tissue slices, pathological changes were not noted in the control and control-medication groups. However, pancreatic dropsy, acinus necrosis, hemorrhage, steatonecrosis, and inflammatory cell infiltration were observed in the other groups, which indicated that sporadic necrosis occurred and protein infiltrate was markedly alleviated. Infiltration of inflammatory cells was obvious in the AP medication groups. There was also a reduction in the pathologic score in the AP medication groups. The results described above indicate that rheum might ameliorate the pathological changes in rats with AP.

\section{Effect on metabolism of the major components of rheum}

Emodin, chrysophanol, rhein, and 2,5-dimethyl-7methoxy chromone are the main components of rheum (Yang et al., 1999). A study by Bloomer, Stagliano, and Gazzillo (1993) indicated that the chemical shifts of emodin, chrysophanol, rhein, and 2,5-dimethyl-7methoxy chromone were $\delta 7.10, \delta 7.34, \delta 7.42$, and $(\delta 7.82$, $\delta 7.9)$, respectively. In the test, chrysophanol, rhein, and 2,5-dimethyl-7-methoxy chromone increased in the control-medication group compared with the control group. Similarly, there were increased levels of emodin and 2,5-dimethyl-7-methoxy chromone in the medication groups, which indicated that rheum is efficiently absorbed via oral gavage. As well as emodin and 2,5-dimethyl-7methoxy chromone, chrysophanol and rhein were present at the same levels in the control and medication groups. It is possible that the serum concentrations of chrysophanol and rhein decreased as the drug was metabolized. However, residual emodin and 2,5-dimethyl-7-methoxy chromone were detected in the serum because their contents in rheum were much higher than those of chrysophanol and rhein (Bloomer, Stagliano, Gazzillo, 1993). Moreover, Shia et al. (2009) suggested that rhein, emodin, and chrysophanol glucuronides were predominant in the blood via oral administration; in our studies, emodin, chrysophanol, rhein, and 2,5-dimethyl-7-methoxy chromone were still significantly distinguishable on the loading plots compared with the other metabolites, which might be attributed to the shortening of persistence time and pathological changes.

\section{Effect on carbohydrates, lipids, protein metabolism, and nucleic acid metabolism}

$\alpha$-ketoglutaric acid, succinic acid, malic acid, and citric acid are the main intermediate products in the tricarboxylic acid (TCA) cycle. In the TCA, acetyl CoA condenses with oxaloacetic acid to produce citric acid. Isocitric acid produces $\alpha$-ketoglutaric acid by oxidative decarboxylation, succinyl CoA transforms to succinic acid by releasing adenosine triphosphate (ATP), and fumaric acid produces malic acid by hydration. In our research, the levels of $\alpha$-ketoglutaric acid, succinic acid, malic acid, and citric acid increased in the control-medication groups, but no significant differences were noted in the other groups compared with the control group. However, in the AP groups, succinic acid decreased significantly. As a result, probably related to a negative chemical equilibrium shift in TCA that led to the accumulation of intermediate metabolites, the activation of TCA in the AP model rats presumably occurred to a small extent, and rheum was able to significantly reduce this activation in normal rats but not in AP rats.

During glycolysis, 2-phosphoglyceric acid produces phosphoenolpyruvate by dehydration. The phosphoric acid from phosphoenolpyruvate is transferred to adenosine diphosphate (ADP), and pyruvic acid and ATP are produced. The process ultimately produces lactic acid and $\left[\mathrm{NAD}^{+}\right]$(Murray et al., 2003). In our test, an increase in the level of phosphoenolpyruvate and lactic acid occurred in the AP groups compared with the control group. This suggested an acceleration of glycolysis in the AP rats, which was consistent with reports of anoxia and decreased aerobic respiration ratio caused by pulmonary injury and dehydration in AP patients (Surbatovic et al., 2005; Xie, 
$\mathrm{Xu}, 2008)$. In the medication groups, phosphoenolpyruvate was present at the same level as in the control group, although an increase in lactic acid was also observed. This result indicates that rheum might increase the level of glycolysis by decreasing phosphoenolpyruvate and accelerating the process.

Compared with the control group, the level of lipids decreased and the level of $\beta$-hydroxybutyric acid increased in the control-medication group. This might have been induced by the acceleration of lipid metabolism, because fatty acids are decomposed to ketones and transferred to acetyl CoA in the liver (Berg, Tymoczko, Stryer, 2002). In the AP groups, both acetoacetic acid and $\beta$-hydroxybutyric acid increased rapidly, indicating that the hydrolysis of fatty acids in the AP rats was accelerated. In combination with the acceleration of glycolysis in the AP rats, aerobic respiration might not have been able to provide sufficient energy, and lipid metabolism acted as a supplement. In the medication groups, there was no change in ketone metabolites compared with the control group, which might be attributed to a reverse in the aerobic respiration ratio, indicating that rheum slows energy metabolism.

Moreover, the lactic acid/pyruvic acid (L/P) ratio was directly proportional to the level of tissue anoxia, and the L/P balance was always affected by the [NADH]/ $\left[\mathrm{NAD}^{+}\right]$ratio (Shia et al., 2009). The $[\mathrm{NADH}] /\left[\mathrm{NAD}^{+}\right]$ ratio decreased in the AP groups and increased in the control-medication and AP-medication groups. Based on the results, the rate of glycolysis was normal, and rheum probably prevented inhibition of the energizing process, which can produce a higher $[\mathrm{NADH}] /\left[\mathrm{NAD}^{+}\right]$ ratio through a negative equilibrium shift, along with a deceleration of lipid metabolism.

The levels of valine and histidine only increased in the AP groups compared with the control group, which indicated an acceleration of protein catabolism. Considering the decreased ratio of aerobic respiration, we conjectured that the decomposition of proteins provided energy in the AP groups. Rheum produced an increase in the ratio of aerobic respiration and prohibited protein catabolism, as indicated by the absence of a significant difference between the control and medication groups.

Increased adenine and pyrimidine in the AP groups indicated accelerated nucleic acid metabolism. The level of formic acid also decreased in the AP groups, which proved that the consumption of formic acid was lifted following the improvement in the synthesis of purine nucleotides. In the medication and control groups, adenine, pyrimidine, and formic acid were present at the same levels, indicating that an equilibrium of nucleic acids occurred, and rheum stabilized nucleic acid metabolism.

\section{Effect on metabolism of digestion and excretion}

Creatinine and urea nitrogen levels are standard indicators for the evaluation of renal function. The creatinine content decreased in the control-medication group, and increased in the AP and AP-medication groups. According to some reports, emodin promotes creatine excretion (Yu et al., 2002), which is in-line with the results of the control-medication group. This was corroborated by a report that AP could cause pathological changes in kidneys and induces urinary abnormalities (oliguria, proteinuria, hematuria, or renal failure) with an occurrence rate of 50\% (Xie et al., 2003). The increases in the levels of creatinine and urea nitrogen in the AP modeling groups confirmed the phenomenon. Furthermore, there was no significant difference in the level of urea nitrogen in the medication groups compared with the control group, which possibly indicates rheum as a prompt therapy for renal abnormality in AP model rats.

Bilirubin is one of the main components in the hepato-enteric circulation. In our test, the purgation effect of rheum (Yamamoto et al., 2000) possibly led to a decrease in the level of bilirubin. The level of bilirubin decreased significantly in the control-medication and medication groups, which corroborated the data from related reports on the purgation effect.

\section{Other metabolites}

Compared with the control group, the levels of cholestanone and testosterone increased in the controlmedication group. Rheum possibly promotes growth and development. However, it did not have a significant effect in the AP rat models, possibly owing to the abnormality of metabolism. TMAO is the degradation product of choline, and an increase of TMAO always indicates rupture of the cell membrane (Grifin et al., 2001). Therefore, the increase of TMAO in the serum samples from the AP and medication groups was induced by the digestion of pancreatic tissue. Hippuric acid and PAG are usually produced by intestinal bacteria (Delaney et al., 2004; Phipps et al., 1998), and PAG is the end product of phenylalanine in rodents (James et al., 1972). The increase in the levels of hippuric acid and PAG in the AP groups indicated intestinal bacteria entering the blood, whereas the remaining hippuric acid in the medication groups indicated inhibition by rheum. The decreased 5-HT level in the AP groups might have been caused by the rupture of islets of Langerhans in the AP rats, because 5-HT is principally secreted by the islets of Langerhans (Mann, Brent, Arango, 2001). 
In general, the metabolism of fat, protein, and nucleic acids was accelerated, and the aerobic respiration ratio was reduced in the AP rats. During AP, the cell membrane ruptures, intestinal bacteria enter the blood, and circulatory, respiratory, urinary, and digestive system abnormalities occur. The results were consistent with previous reports that systemic inflammatory response syndrome (SIRS) and multiple organ failure (MOF) are caused by AP (Schlosser et al., 2002; Isenmann, Rau, Beger, 2001; Buter et al., 2002). When rheum was administered to the rats, multiple metabolic abnormalities such as the occurrence of amines were not observed, even though several metabolic pathways were impacted. This indicates that rheum might improve energization in organisms. Previous studies have shown that the therapeutic effect of rheum is associated with three underlying mechanisms: (1) rheum increases the level of testosterone in an organism, and leads to accelerated regeneration of erythrocytes (Istvan, 2005); (2) rheum is a traditional Chinese medicine with a therapeutic effect on acute pulmonary injury (Surbatovic et al., 2005), and can therefore improve the efficiency of lung ventilation; and (3) rheum exerts anti-inflammatory and antibiotic effects (Zhou et al., 2006; Wu et al., 2005), both of which decrease vascular permeability and increase relative blood volume, thereby improving oxygen supply in the blood capillaries. Moreover, the elimination of metabolic products via the purgation effect of rheum is also a critical mechanism.

\section{CONCLUSION}

Analysis of serum samples using ${ }^{1} \mathrm{H}$ NMR and PLSDA revealed that $7.5 \%$ rheum exerted therapeutic action on acute pancreatitis rat models, which was consistent with the pathology evaluation. By profiling endogenous metabolites, we discovered that the therapeutic effects could be caused by an improvement in energization and the elimination of metabolic products in the organism. The significant differences in the levels of metabolites among the test groups also supported the potential use of NMR-based metabonomic analysis for the investigation of traditional Chinese drugs.

\section{ACKNOWLEDGEMENTS}

We sincerely thank the staff at the Sichuan University Analytical and Testing Center for carrying out the NMR spectroscopic analyses.

\section{REFERENCES}

AMMANN, R.W.; ADLER, G.; BUCHLER, M.W. Pancreatitis: advances in pathobiology, diagnosis and treatment. Germany: Falk Symposium 143, 2004. Sect. 1.

BANKS, P.A.; BOLLEN, T.L.; DERVENIS, C.; GOOSZEN, H.G.; JOHNSON, C.D. Classification of acute pancreatitis-2012: revision of the Atlanta classification and definitions by international consensus. Gut., v.62, n.1, p.102-111, 2013.

BARRETO, S.G.; RODRIGUES, J. Acute pancreatitis in Goa-a hospital based study. J. Ind. Med. Assoc., v.106, n.9, p.575578, 2008.

BERG, J.M.; TYMOCZKO J.L.; STRYER, L. Biochemistry. 5. ed. New York: W.H. Freeman and Company, 2002. 894p.

BLOOMER, J.L.; STAGLIANO, K.W.; GAZZILLO, J.A. Preparation of functionalized juglone acetates and juglone via 1,4-dimethoxynapthalene derivatives: synthesis of anthraquinones related to Rhein and Aloe emodin. J. Org. Chem., v.58, n.27, p.7906-7912, 1993.

BRAGANZA, J.M. Towards a novel treatment strategy for acute pancreatitis. Digestion, v.63, n.3, p.69-91, 2001.

BUTER, A.; IMRIE, C.W.; CARTER C.R.; EVANS, S.; MCKAY, C.J. Dynamic nature of early organ dysfunction determines outcome in acute pancreatitis. Br. J. Surg., v.89, n.3, p.298-302, 2002.

CHEN, X.; YANG, Y.X.; WANG, S.M.; LIANG, S.W. Study on effects of extract in Naomaitong Formula on cerebral ischemia-reperfusion model based on NMR metabolomics. Chin. Trad. Herbal Drugs, v.43, p.97-102, 2012.

CHINESE PHARMACOPOEIA COMMISSION. Pharmacopoeia of the People's Republic of China. Beijing: Chemical Industry Press, 2010. v. 1.

CROCKER, J.T. Acute Pancreatitis. Hosp. Med. Clin., v.1, n.2, p.209-222, 2012.

DELANEY, J.; NEVILLE, W.A.; SWAIN, A.; MILES, A.; LEONARD, M.S.; WATERFIELD, C.J. Phenylacetylglycine, a putativebiomarker of phospholipidosis: its origins and relevance tophospholipid accumulation using amiodarone treated rats asa model. Biomarkers, v.9, n.3, p.271-90, 2004. 
DEMBINSKI, A.; WARZECHA, Z.; CERANOWICZ, P.; WARZECHAA, A.M.; PAWLIKA, W.W. Dual, timedependent deleterious and protective effect of anandamide on the course of cerulein-induced acute pancreatitis. Role of sensory nerves. Eur. J. Pharmacol., v.591, n.1-3, p.284292, 2008.

GAISANO, H.Y.; GORELICK, F.S. New insights into the mechanisms of panceatitis. Gastroenterology, v.136, n.7, p.2040-2044, 2009.

GAO, Y.; HE, R.S. Clinical observation on the treatment of acute pancreatitis by injecting rheum in gastric canal. Shizhen Chin. Med. Drugs, v.18, n.7, p. 1751-1752, 2007.

GE, Q.X.; CHEN, K.; WANG, H. Research procession of tranditional Chinese drugs on acute pancreatitis. Drug Adm. Assessm. China Hosp., v.8, n.6, p. 474-477, 2008.

GRIFFIN, J.L.; MANN, C.J.; SCOTT, J.; SHOULDERS C.C.; NICHOLSON, J.K. Choline containing metabolites during cell transfection: an insight into magnetic resonance spectroscopy detectable changes. FEBS Lett., v.509, n.2, p.263-266, 2001.

GU, Y.Z.; WANG, Z.P. Clinical observation on the treatment of hypopathy acute pancreatitis by Integrated Traditional Chinese Medicine and Western Medicine (40 examples). Mod. Clin. Med., v.35, n.6, p.428-429, 2009.

ISENMANN, R.; RAU, B.; BEGER, H.G. Early severe acute pancreatitis: characteristics of a new subgroup. Pancreas, v.22, n.3, p.274-278, 2001.

ISTVAN, B. Neuroendocrine regulation of natural immunity. NeuroImmune Biol., v.5, p.215-262, 2005.

JAMES, M.O.; SMITH, R.L.; WILLIAMS, R.T.; REIDENBERG $M$. The conjugation of phenylacetic acid in man, subhumanprimates and some non-primate species. Proc. $R$. Soc. B. Biol. Sci., v.182, n.1066, p.25-35, 1972.

JIANGSU NEW MEDICAL COLLEGE. Dictionary of chinese materia medica. Shanghai: Shanghai People s Publishing House, 1997.

JI, B.; CHEN, X.Q.; MISEK, D.E.; KUICK, R.; ANASH, S.; MST, S.; NAJARIAN, R. Pancreatic gene expression during the initiation of acute pancreatitis: identification of BGR-1 as a key regulator. Physiol. Genomics, v.14, p.59-72, 2003.
KOSTYRNOI, O.V. Changes in acute pancreatitis treatment program. Klinicheskaia Khirurgiia, v.10, p.26-28, 2012.

LIU, X.B.; JIANG, J.M.; HUANG, Z.W.; TIAN, B.L.; HU, W.M.; XIA, Q.; CHEN, G.Y.; LI, Q.S.; YUAN, C.X.; LUO, C.X.; YAN, L.N.; ZHANG, Z.D. Clinical study on the treatment of severe acute pancreatitis by Integrated Traditional Chinese Medicine and Western Medicine. $J$. Sichuan Univ.(Med. Sci. Ed.)., v.35, n.2, p. 204-208, 2004.

LOMBARDI, B.; ESTES, L.W.; LONGNECKER, D.S. Acute hemorrhagic pancreatitis (massive necrosis) with fat necrosis induced in mice by DL-ethionine fed with a choline-deficient diet. Am. J. Pathol., v.79, n.3, p.465-480, 1975.

MANN, J.J.; BRENT, D.A.; ARANGO, V. The neurobiology and genetics of suicide and attempted suicide: a focus on the serotonergic system. Neuropsychopharmacology, v.24, n.5, p.467-477, 2001.

MURRAY, R.K.; GRANNER, D.K.; MAYES, P.A.; RODWELL, V.W. Harper's illustrated biochemistry. 26. ed. New York: McGraw Hill, 2003. 693p.

NICHOLSON, J.K.; WILSON, I.D. High resolution proton magnetic resonance spectroscopy of biological fluids. Prog. Nucl. Mag. Res. Spect., v.21, n.4-5, p.449-501, 1989.

NORMAN, J.G.; FINK, G.W.; DENHAM, W.; YANG, J.; CARTER, C.; SEXTON, C.; FALKNERR, J.; GOWERR, W.R.; FRANZ, M.G. Tissue-specific cytokine production during experimental acute pancreatitis. A probable mechanism for distant organ dysfunction. Digest Dis. Sci., v.42, n.8, p.1783-1788, 1997.

PHIPPS, A.N.; STEWART, J.; WRIGHT, B.; WILSON, I.D. Effect of diet on the urinary excretion of hippuric acid and other dietary-derived aromatics in rats. A complex interaction between diet, gut microflora and substrate specificity. Xenobiotica, v.28, n.5, p.527-537, 1998.

SCHLOSSER, W.; SCHLOSSER, S.; RAMADANI, M.; GANSAUQE, F.; GANSAUGE, S.; BEGER, H.G. Cyclooxygenase- 2 is over-expressed in chronic pancreatitis. Pancreas, v.25, n.1, p.26-30, 2002.

SEWING, K.F.; ALBINUS, M. Effect of gastrin 1 and caerulein on gastric acid secretion in rats. J. Pham. Pharmacol., v.21, n.1, p.58-59, 1969. 
SHIA, C.S.; JUANG, S.H.; TSAI, S.Y.; CHANG, P.H.; KUO, S.C.; HOU, Y.C.; CHAO, P.D. Metabolism and pharmacokinetics of anthraquinones in Rheum palmatum in rats and ex vivo antioxidant activity. Planta Med., v.75, n.13, p.1386-92, 2009.

SHI, C.; WU, C.Q.; CAO, A.M.; SHENG, H.Z.; YAN, X.Z.; LIAO, M.Y. NMR-spectroscopy-based metabonomic approach to the analysis of Bay41-4109, a novel anti-HBV compound, induced hepatotoxicity in rats. Toxicol. Lett., v.173, n.3, p. 161-167, 2007.

SURBATOVIC, M.; JOVANOVIC, K.; RADAKOVIC, S.; FILIPOVIC, N. Pathophysiological aspects of severe acute pancreatitis-associated lung injury. Srp. Arh. Celok Lek, v.133, n.1-2, p.76-81, 2005.

WEI, L.; LIAO, P.; WU, H.; LI, X.; PEI, F.; LI, W.; WU, Y. Toxicological effects of cinnabar in rats by NMR-based metabolic profiling of urine and serum. Toxicol. Appl. Pharmacol., v.227, n.3, p.417-429, 2008.

WISHART, D.S.; TZUR, D.; KNOX, C.; EISNER, R.; GUO, A.C.; YOUNG, N.; CHENG, D.; JEWELL, K.; ARNDT, D.; SAWHNEY, S. HMDB: the human metabolome database. Nucleic Acids Res., v.35, Suppl. 1, p.D521-D526, 2007.

WU, Y.W.; GAO, W.Y.; XIAO, X.H.; LIU, Y. Calorimetric investigation of the effect of hydroxyanthraquinonesin Rheum officinale Baill on Staphylococcus aureus growth. Thermochimica Acta, v.429, p.167-170, 2005.

XIAO, P.G. New data of Chinese Materia Medica. Beijing: Chemical Engineering Publishing House, 2002. v.1, p.6676.

XIE, H.L.; GONG, D.H.; JI, D.X.; XU, B.; LIU, Y.; LI, L.S.; LI, W.Q.; LI, J.S. Effect of continuous high capacity hemofiltration on C-reaction protein in acute pancreatitis patients. J. Renal Dis. Dialys. Transplant., v.12, n.1, p.1014, 2003.
XIE, J.F., XU, P.. Review of pathogenesis on acute pancreatitis related pulmonary injuries. International digestion journal. v.28, n.6, p.449-451, 2008.

YAMAMOTO, M.; MIURA, N.; OHTAKE, N.; AMAGAYA, S.; ISHIGE, A.; SASAKI, H.; KOMATSU, Y.; FUKUDA, K.; ITO, T.; TERASAWA, K. Genipin, ametabolite derived from the herbal medicine Inchin-ko-to, and suppression of Fas-induced lethal liver apoptosis in mice. Gastroenterology, v.118, n.2, p.380-389, 2000.

YANG, F.; ZHANG, T.; TIAN, G.; CAO, H.F.; LIU, Q.H.; ITO, Y. Preparative isolation and purification of hydroxyanthraquinones from Rheum officinale Baill by high-speed counter-current chromatography using $\mathrm{pH}$ modulated stepwise elution. J. Chromatogr. A, n.858, n.1, p.103-107, 1999.

YU, C.X.; XIAO, P.; SU, Z.H.; GAO, Y.L. Review of clinical application on rheum. Drug Adm. Assessm. China Hosp., v.2, n.6, p.359-362, 2002.

ZHANG, W.Q.; GUO, H.Z.; ZHANG, X.Q.; LIU, Q.Y. Dissolution determination of Shuanghuanglian capsules by HPLC analysis assisted with principal component analysis. China J. Chin. Mat. Med., v.38, n.7, p.985-989, 2013.

ZHOU, X.; SONG, B.; JIN, L.H.; HU, D.Y.; DIAO, C.L.; XU, G.F.; ZOU, Z.Z.; YANG ANG, S. Isolation and inhibitory activity against ERK phosphorylation of hydroxyanthraquinones from rhubarb. Bioorg. Med. Chem. Lett., v.16, n.3, p.563-568, 2006.

Received for publication on $24^{\text {th }}$ January 2015 Accepted for publication on $14^{\text {th }}$ July 2017 